\title{
Autophagy, and BiP level decrease are early key events in retrograde degeneration of motoneurons
}

\author{
C Penas ${ }^{1}$, M Font-Nieves ${ }^{2}$, J Forés ${ }^{3}$, V Petegnief ${ }^{2}$, A Planas $^{2}, \mathrm{X} \mathrm{Navarro}^{1}$ and C Casas ${ }^{*, 1}$
}

Disconnection of the axon from the soma of spinal motoneurons (MNs) leads either to a retrograde degenerative process or to a regenerative reaction, depending on the severity and the proximity to the soma of the axonal lesion. The endoplasmic reticulum (ER) is a continuous membranous network that extends from the nucleus to the entire cytoplasm of the neuronal soma, axon and dendrites. We investigated whether axonal injury is sensed by the ER and triggers the activation of protective mechanisms, such as the unfolded protein response (UPR) and autophagy. We found early (at 3 days) accumulation of beclin1, LC3II and Lamp-1, hallmarks of autophagy, in both degenerating MNs after spinal root avulsion and in non-degenerating MNs after distal nerve section, although Lamp-1 disappeared by 5 days only in the former. In contrast, only degenerating MNs presented early activation of IRE1 $\alpha$, revealed by an increase of the spliced isoform of Xbp1 and accumulation of ATF4 in their nucleus, two branches of the UPR, and late BiP downregulation in association with cytoskeletal and organelle disorganization. We conclude that BiP decrease is a signature of the degenerating process, as its overexpression led to an increase in MN survival after root avulsion. Besides, Bcl2 is strongly implicated in the survival pathway activated by BiP overexpression.

Cell Death and Differentiation (2011) 18, 1617-1627; doi:10.1038/cdd.2011.24; published online 25 March 2011

The mechanisms involved in degeneration and regeneration of adult spinal motoneurons (MNs) following axotomy and target deprivation are still poorly understood. Peripheral nerve injuries produce the disconnection and subsequent degeneration of the distal axon from the body of damaged neurons. The soma of axotomized neurons undergoes a series of phenotypic changes termed 'chromatolysis', which arise from dispersal of large Nissl bodies due to disintegration of stacked rough endoplasmic reticulum. ${ }^{1}$ The accompanying metabolic changes are necessary for axonal regeneration, but the mechanisms involved in the neuronal reaction remain partially unknown. ${ }^{2}$ However, in some instances the neuron is unable to survive the axotomy, particularly when the lesion is produced at sites near to the neuronal soma. Thus, after distal axotomy a nonsignificant loss of motoneurons has been found,$^{3}$ whereas lesions at the spinal root, due to traction or avulsion, in the adult lead to progressive and marked loss of the axotomized MNs. ${ }^{4,5}$ There exist controversial studies about the processes that lead to this $\mathrm{MN}$ degeneration; some authors claimed that it is mainly an apoptotic process, ${ }^{4}$ whereas others pointed to a rather necrotic death. ${ }^{6,7}$ Axotomy produces an initial rupture of the plasma membrane that leads to calcium influx 8 and disassembly of the cytoskeleton, triggering long-lasting electrophysiological disturbances involving the entire neuron. ${ }^{9}$ Besides, axotomy interrupts retrograde axonal transport of target-derived trophic factors to the neuronal perikarya. The lack of these trophic factors in turn initiates the cell responses of neurons and surrounding glial after axotomy. ${ }^{10}$

The endoplasmic reticulum (ER) is a dynamic network of interconnected membrane tubules that essentially reaches every part of the cell, including dendrites ${ }^{11}$ and axons ${ }^{12}$ in neurons. ER is associated with microtubules ${ }^{13}$ and largely contributes to local calcium homeostasis and signaling, and protein and lipid biosynthesis. Thus, the ER may be one of the main organelles that sense the rupture of the axon and react sending back information to the soma. Disturbances in calcium homeostasis may lead to ER stress that produces accumulation of unfolded or misfolded proteins in the ER lumen, ${ }^{14}$ which takes place in several neurodegenerative events. ${ }^{15,16} \mathrm{ER}$ stress leads to the activation of self-protective mechanisms that include the ER-associated protein degradation (ERAD) pathway, ${ }^{17}$ the unfolded protein response (UPR), and autophagy to avoid cell damage, although under conditions of severe ER stress, it may activate cell death programs as well. ${ }^{18}$ The UPR is triggered by $\mathrm{BiP}$, a reticulumresident chaperone, when unbound from three major effectors: ${ }^{19}$ the RNA-activated protein kinase-like ER kinase

\footnotetext{
${ }^{1}$ Group of Neuroplasticity and Regeneration, Institute of Neurosciences, Department of Cell Biology, Physiology and Immunology, Universitat Autònoma de Barcelona, and Centro de Investigación Biomédica en Red sobre Enfermedades Neurodegenerativas (CIBERNED), Spain; ${ }^{2}$ Department of Brain Ischemia and Neurodegeneration, Institute for Biomedical Research of Barcelona (IIBB), Spanish Research Council (CSIC), Institut d'Investigacions Biomèdiques August Pi Sunyer (IDIBAPS), Barcelona, Spain and ${ }^{3}$ Hand and Peripheral Nerve Unit, Hospital Clínic i Provincial, Universitat de Barcelona, Barcelona, Spain

*Corresponding author: C Casas, Department of Cell Biology, Physiology and Immunology, Institute of Neurosciences, Unitat de Fisiologia Mèdica, Edif. M, Universitat Autònoma de Barcelona, E-08193 Bellaterra, Spain. Tel: + 34 935811966; Fax: + 34 935812986; E-mail: Caty.Casas@uab.cat

Keywords: spinal root avulsion; axotomy; motoneuron; neurodegeneration; endoplasmic reticulum stress; autophagy

Abbreviations: ATF4, activating transcription factor 4; ATF6 $\alpha$, activating transcription factor 6 alpha; BAD, Bcl-2-associated death promoter; BiP, immunoglobulin heavy chain-binding protein; ChAT, choline acetyltransferase; Grp78, glucose-regulated protein; elF2 $\alpha$, eukaryotic translation initiation factor 2a; ER, endoplasmic reticulum; ERAD, ER-associated protein degradation; GADD153/CHOP, growth arrest- and DNA damage-inducible gene; GFAP, glial fibrillar acidic protein; IRE1 $\alpha$, inositol-requiring protein-1 alpha; LC3, microtubule-associated protein 1 light chain 3; IB4, isolectin B4; MN, motoneuron; PERK, PRK (RNA-dependent protein kinase)like ER kinase; UPR, unfolded protein response; XBP-1, X-box binding protein-1

Received 20.5.10; revised 09.2.11; accepted 10.2.11; Edited by D Rubinsztein; published online 25.3.11
} 
(PERK), inositol-requiring protein-1 alpha (IRE1 $\alpha$ ), and activating transcription factor- 6 alpha (ATF6 $\alpha$ ). ${ }^{20}$ In addition, ER stress could also induce macroautophagy (referred hereafter as autophagy) activation. ${ }^{21-23}$ Autophagy is a nonstop life-sustaining renewal process that is active under normal conditions and is further enhanced in response to tissue injury. It involves the formation of double membrane cisternae, which engulf cytoplasmic materials or whole organelles to become vacuoles called autophagosomes that fuse with lysosomes for degrading its content. ${ }^{24}$ During the formation of autophagosomal membranes, cytosolic microtubule-associated protein light chain 3 (LC3I) is conjugated to phosphatidylethanolamine ${ }^{25}$ to convert to a membrane bound protein, LC3-II, becoming a structural component of the double-membrane cisterns or autophagosomes. Beclin-1 is required for autophagy initiation of cytoplasmic proteins under starvation conditions. Both Beclin-1 and LC3II are considered hallmarks of autophagy initiation and propagation. ${ }^{26} \mathrm{BiP}$ is also required for stress-induced autophagy. ${ }^{27}$ In cells, in which BiP expression is knocked down, despite spontaneous activation of UPR pathways and LC3 conversion, autophagy is blocked and the ER is massively expanded and disorganized. ${ }^{27}$

In this study, we aimed to investigate whether ER stress and autophagy are involved in the degeneration of MNs after spinal root avulsion, and compared this lesion with a distal nerve injury that does not produce $\mathrm{MN}$ degeneration.

\section{Results}

Degenerating motoneurons accumulate ATF4 early after root avulsion. We investigated the presence of ER stress markers in degenerating MNs after root avulsion by analyzing which of the three branches of the UPR were activated. One branch is mediated by ATF6 $\alpha$ (90 KDa), a ER resident protein that, when unbound to $\mathrm{BiP}$ due to ER stress, is cleaved in the Golgi apparatus and shed a $50 \mathrm{kDa}$ fragment. ${ }^{19}$ We did not detect any cleavage of ATF $6 \alpha$ in the ventral horns of the L4-L5 segments in the avulsed or the axotomized spinal cords at any time tested (Figure 1). A second branch of the UPR is mediated by PERK, activation of which inhibits the translation initiation factor elF $2 \alpha$ by phosphorylation, thereby reducing protein synthesis. ${ }^{19}$ One exception is the transcription factor ATF4 that escapes from the global shut-down translation promoted by elF $2 \alpha$ phosphorylation. ${ }^{20}$ Although we did not observe the presence of phosphorylated elF2 $\alpha$ at any time after lesion (Figure 1), we found an increase in ATF4 immunoreactivity in MNs at both sides of the ventral horn from $3 \mathrm{dpo}$, and with maximal expression at 5 dpo after root avulsion (Figure 1, bottom). In contrast, such increase was not observed after distal sciatic nerve lesion (Figure 1). To further characterize this pathway, we looked for the presence of the pro-apoptotic factor $\mathrm{CHOP}$, coding gene of which is a main target of ATF4. No significant differences were detected regarding the transcript or protein levels of Chop in the avulsed ventral horns from $3 \mathrm{dpo}$, by quantitative real-time PCR, western blot, and immunohistochemistry (Figure 2). Besides, we did not find signs of apoptotic activation, neither caspase 12 or caspase 3
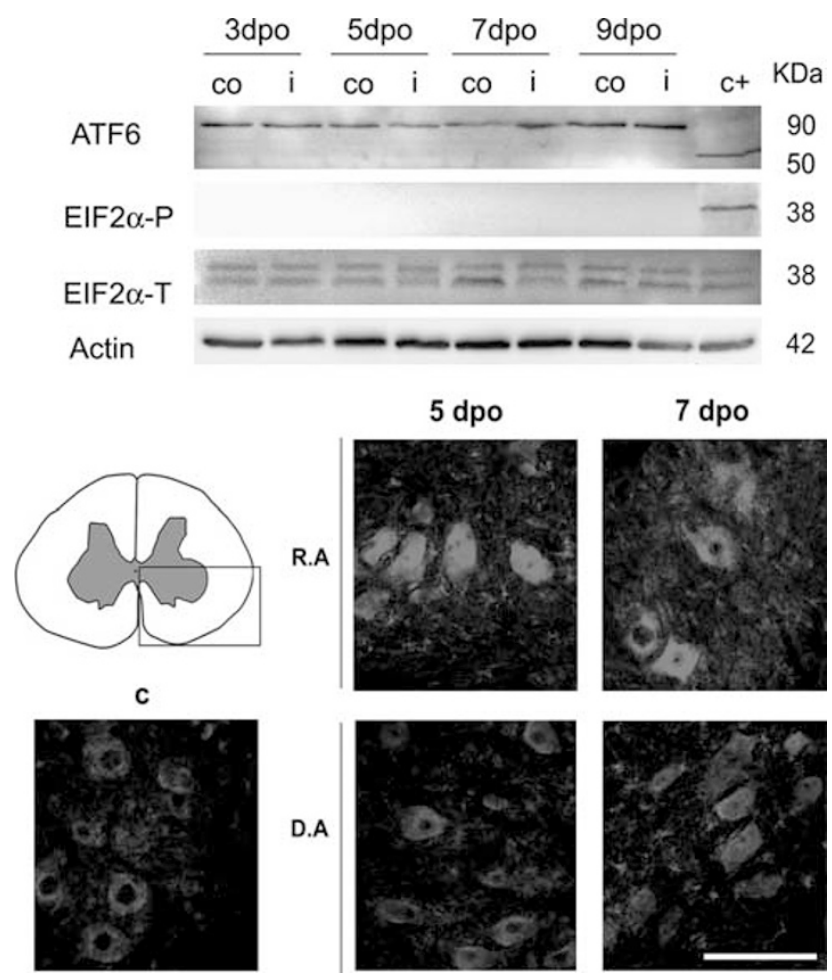

Figure 1 Top: western blots reveal the presence of the full-length $90 \mathrm{KDa}$ fragment of ATF6 $\alpha$ but absence of its cleaved product and lack of phosphorylated elF2 $\alpha$ referred to actin levels or total quantity of elF2 $\alpha$, respectively, in the ventral horns of the L4-L5 spinal cord segments either at the ipsilateral (i) and the contralateral (co) sides at $3,5,7$, and 9 days after root avulsion. Note that we added a positive control from samples of animals submitted to spinal cord injury $(c+)^{40}$ Bottom: microphotographs of the ventral horn spinal cord (highlighted in the left picture) from a immunohistochemical analysis of ATF4 distribution in the spinal MNs of the ipsilateral side from control animals (c), and animals that were submitted to root avulsion (R.A) or to distal axotomy by nerve section (D.A) at 5 and $7 \mathrm{dpo}$. Note the increased immunoreactivity in the R.A model. Bar $=100 \mu \mathrm{m}$

activation nor TUNEL-positive staining in MNs (Figure 2), in spite that at 7-days post avulsion there is loss of more than $25 \%$ of the MNs. ${ }^{5}$

In summary, these results showed that ATF4 protein levels differentially rose in the nucleus of degenerating versus nondegenerating MNs after axotomy. However, this increase did not correlate with $\mathrm{CHOP}$ protein accumulation and was not accompanied by signs of apoptosis in the degenerating MNs.

IRE1 $\alpha-X B P 1$ pathway is differentially activated in avulsed versus axotomized MNs. The third branch of the UPR is mediated through the activation of the ribonuclease activity of IRE $1 \alpha$ that generates a non-conventional processing of the transcript of Xbp1 in the cytoplasm. Once processed, the open reading frame of $X b p 1$ changes and is translated to an active form of a transcription factor (XBP1s, $50 \mathrm{KDa})$, which can bind to several UPR response elements. ${ }^{20}$ The non-processed form (XBP1u) can function as a negative regulator of XBP1s. ${ }^{28}$ We found an increase of XBP1s after root avulsion but an increase of XBP1u after distal nerve lesion, producing that the ratio XBP1s/XBP1u increased significantly in the root-avulsed ventral horn at 
A

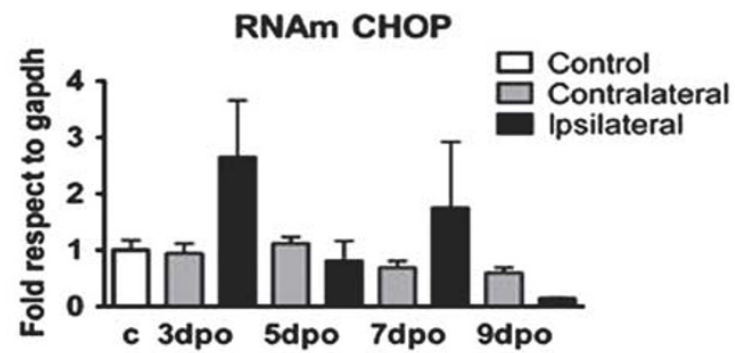

B

$$
\frac{3 d p o}{c o ~ i} \frac{5 d p o}{c o ~ i} \frac{7 d p o}{c o ~ i} \frac{9 d p o}{c o \quad i} \quad c^{+}
$$

$\mathrm{CHOP}$

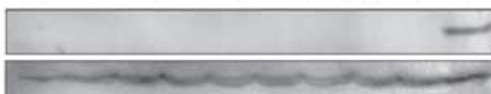

Casp. 12
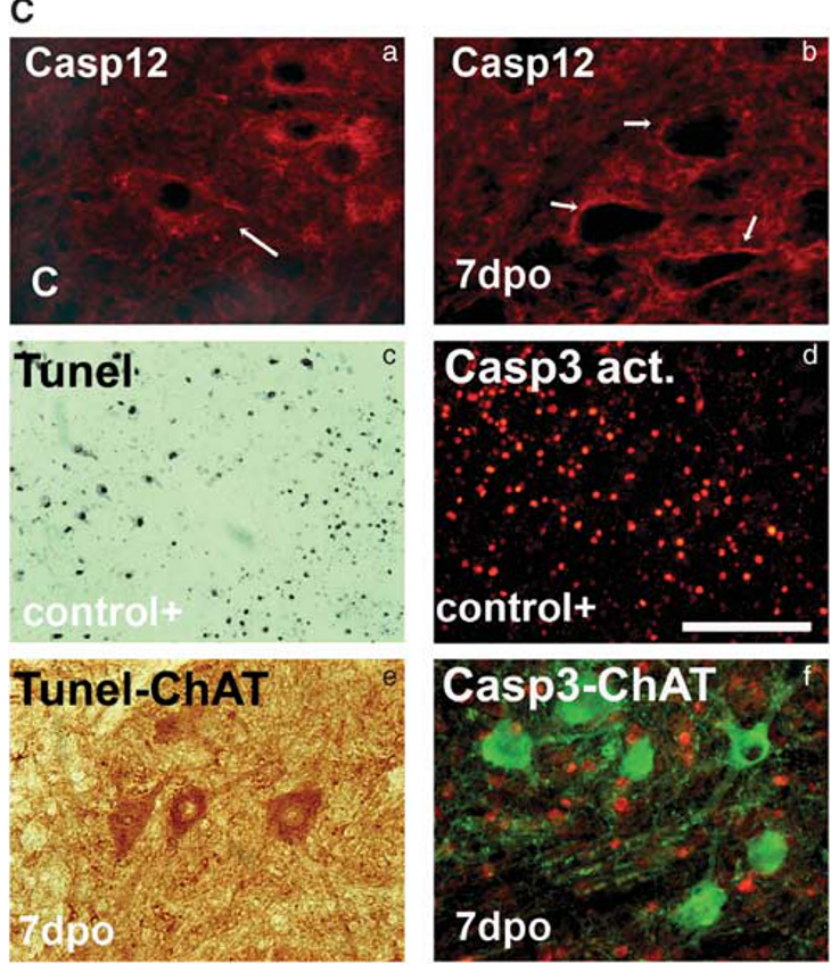

Figure 2 (A) Histogram of mean values obtained by quantitative real-time PCR for Chop mRNA referred to Gapdh levels in the ventral horn of the spinal cord of control rats and in the ipsilateral and contralateral sides of root-avulsed rats. Samples were significantly different according to one-way ANOVA $\left({ }^{\star} P<0.05\right)$, however, post-hoc analysis did not show up differences between ipsilateral and contralateral or control sides. (B) Western blot analysis of CHOP protein levels and full-length $(50 \mathrm{kDa})$ or cleaved fragment $(25 \mathrm{kDa})$ of caspase 12 at different time points in the ipsilateral (i) and contralateral (co) ventral horns of the spinal cord of root-avulsed animals. Note that we added a positive control from samples of animals submitted to spinal cord injury $(\mathrm{c}+)^{40}(\mathrm{C})$ Microphotographs of control and avulsed ventral horns immunostained for caspase 12 (a and $\mathbf{b}$ ), and cleaved caspase 3 (red) (d and f) alone (d) or versus Choline acetyl transferase (ChAT, green) (f) at different times post-injury in control-positive animals (d) or root-avulsed ones (e and f). Note that caspase 12 completely disappears from $7 \mathrm{dpo}$ in the MNs and there is no colocalization between ChAT and cleaved caspase 3 immunostaining. Tunel staining (black) was also performed in a positive control section of brain tissue from an excitotoxic rat model52 (c), and in the root-avulsed model (e) colabeled for ChAT (brown). Bar $=100 \mu \mathrm{m}$
3 dpo in comparison with the nerve distal axotomy model (Figure 3 , top). The immunohistochemical analysis conducted with an anti-panXBP1 revealed that the factor was localized into the nucleus of MNs at the ipsilateral ventral horn of the spinal cord in both models from $3 \mathrm{dpo}$, and thus independently of the isoform upregulated (Figure 3, bottom).

These results suggested that root avulsion produces an activation of the ribonuclease activity of IRE $1 \alpha$, leading to an increase of XBP1s. In contrast, although XBP1u levels increase following distal axotomy/reconnection and nuclearized in MNs, there was not activation of IRE1 $\alpha$ in nondegenerating MNs.

BiP levels are distinctly reduced in degenerating versus non-degenerating motoneurons. We analyzed BiP levels by western blot, as they are crucial to activate the selfprotecting mechanisms of UPR and autophagy. ${ }^{27} \mathrm{BiP}$ levels remained statistically unchanged after root avulsion (Figure 4a). In contrast, in the distally axotomized spinal cords, BiP protein levels increased with a maximum at $5 \mathrm{dpo}$ in both sides of the ventral horn (3.4 \pm 0.2 fold) (Figure $4 a)$. By immunohistochemical analysis, we observed that in degenerating MNs, BiP presented the normal ER localization until $5 \mathrm{dpo}$, and later on it progressively disappeared as shown in Figure $4 \mathrm{~b}$. In contrast, in nondegenerating $\mathrm{MNs}$ of the distal axotomy model, BiP presented a normal localization at all time-points analyzed (Figure 4b). Therefore, it seems that there is a marked and specific difference between degenerating and nondegenerating $\mathrm{MNs}$ regarding $\mathrm{BiP}$ downregulation around 5-7 days post lesion, which is hardly detected by western blot probably because of its sustained expression in glial cells.

In addition to $\mathrm{BiP}$, we analyzed the $\mathrm{Bcl}-2$ family of proteins that are considered critical in the regulation of ER functions, as well as in the transmission of the apoptotic signal from the ER to the mitochondria during ER stress. ${ }^{29}$ We found that $\mathrm{Bcl}-2$ was transiently reduced in non-degenerating $\mathrm{MNs}$ around $5 \mathrm{dpo}$, but permanently reduced in degenerating MNs after root avulsion (Figure $4 b$ ).

Degenerating MNs have disordered organelles and microtubule disassembly. As labeling of BiP and caspase 12, two ER proteins, disappeared by 5-7 dpo, we analyzed the organelles of the secretory pathway in degenerating MNs using structural markers. Using the H69 antibody that labels a structural glycoprotein of the ER membrane, ${ }^{30}$ we observed a progressive decrease in the MNs to be absent by 7 dpo (Figure 5). Similarly, we found that the Golgi apparatus labeled with either the anti-58-KGolgi or the $\alpha$-giantin antibody, presented a fragmented appearance by the same time (Figure 5). In contrast, no obvious alterations were detected in MNs after distal axotomy at the same time points. Contralateral MNs after both lesions maintained the normal immunoreacitivty for these markers (data not shown).

Considering that organization and movement of organelles are maintained by direct linkage to microtubules, ${ }^{31}$ we investigated whether there was any abnormality on the microtubule network. As expected, microtubule-associated protein 2A/B (MAP2A/B) staining disappeared progressively, 

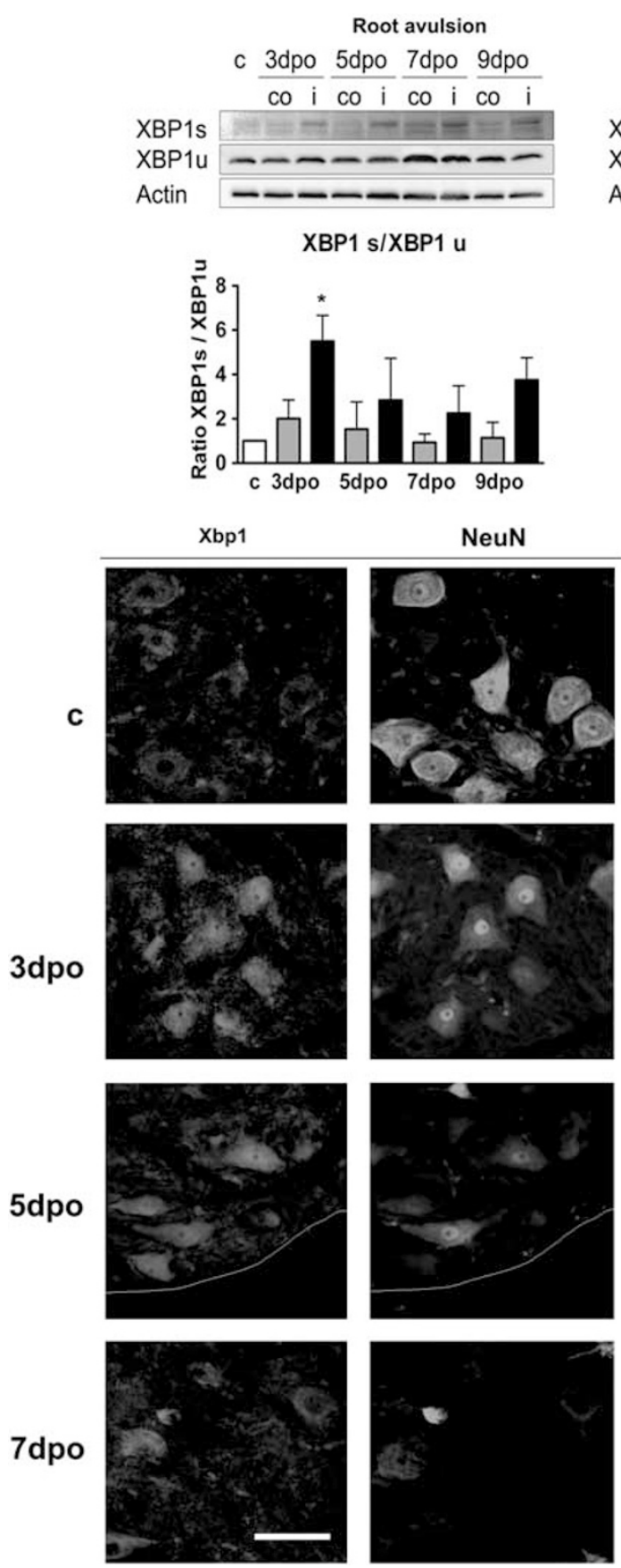
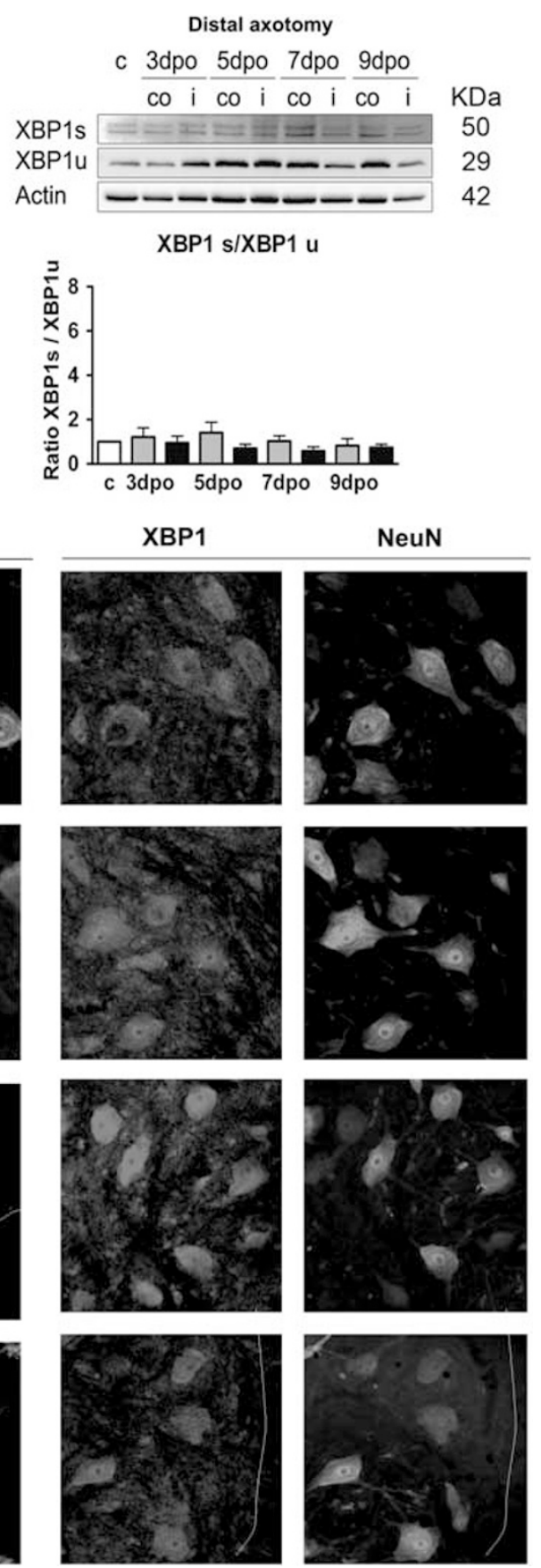

Figure 3 Top: analysis of the presence of the spliced (XBP1s) or uncut (XBP1u) isoform of XBP1 by western blot. Histograms show the mean ratio for each isoform and referred to actin levels in ventral horns of control intact rats (c, empty bars), and of contralateral (gray bars) and ipsilateral (black bars) ventral horns of rats after root avulsion or after distal nerve axotomy. ${ }^{*} P<0.05$ Bottom: microphotographs of transverse sections of the spinal cord of control and axotomized showing the MNs at the ventral horns immunostained with anti-pan-XBP1 colocalizing with neuronal-specific immunostaining for NeuN in both models at different time points. Dotted lines separate white and gray matter at the ventral side of the spinal cord. Bar $=200 \mu \mathrm{m}$

being more evident in the soma of the MNs from $7 \mathrm{dpo}$ onwards after root avulsion (Figure5 and data not shown). In contrast, the immunostaining of MAP2 maintained its normal aspect after distal nerve lesion. On the other hand, $\beta$-tubulin-III staining was unaltered in both models (Figure 5).

These results showed that there is a disorganization of the endomembrane system and microtubule network in root-avulsed MNs, whereas distally axotomized MNs do not show any organelle alteration.

Autophagy is activated in avulsed and axotomized MNs. In light of these alterations in organelles and cytoskeleton and as autophagy is activated upon ER stress as a defensive mechanism for survival, ${ }^{32}$ we investigated 
a
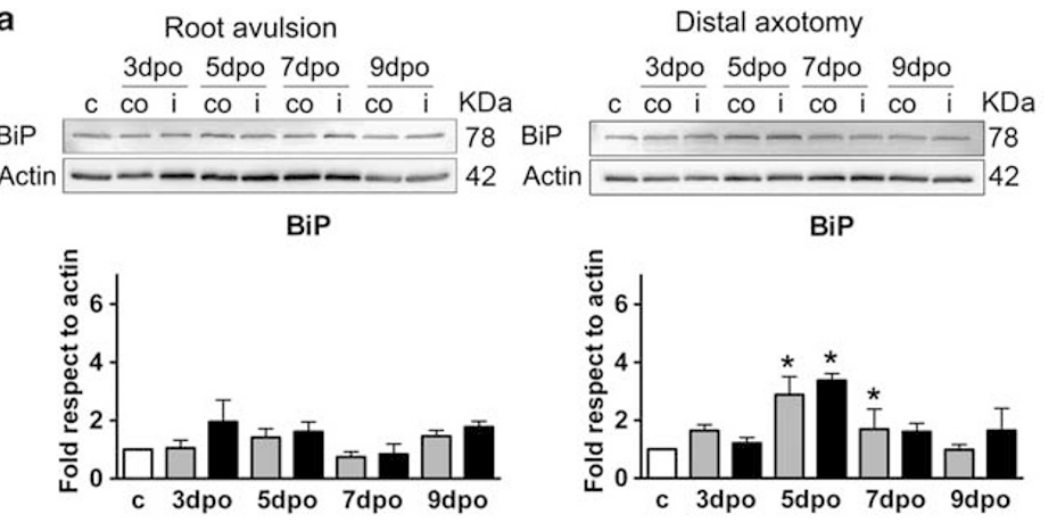

b
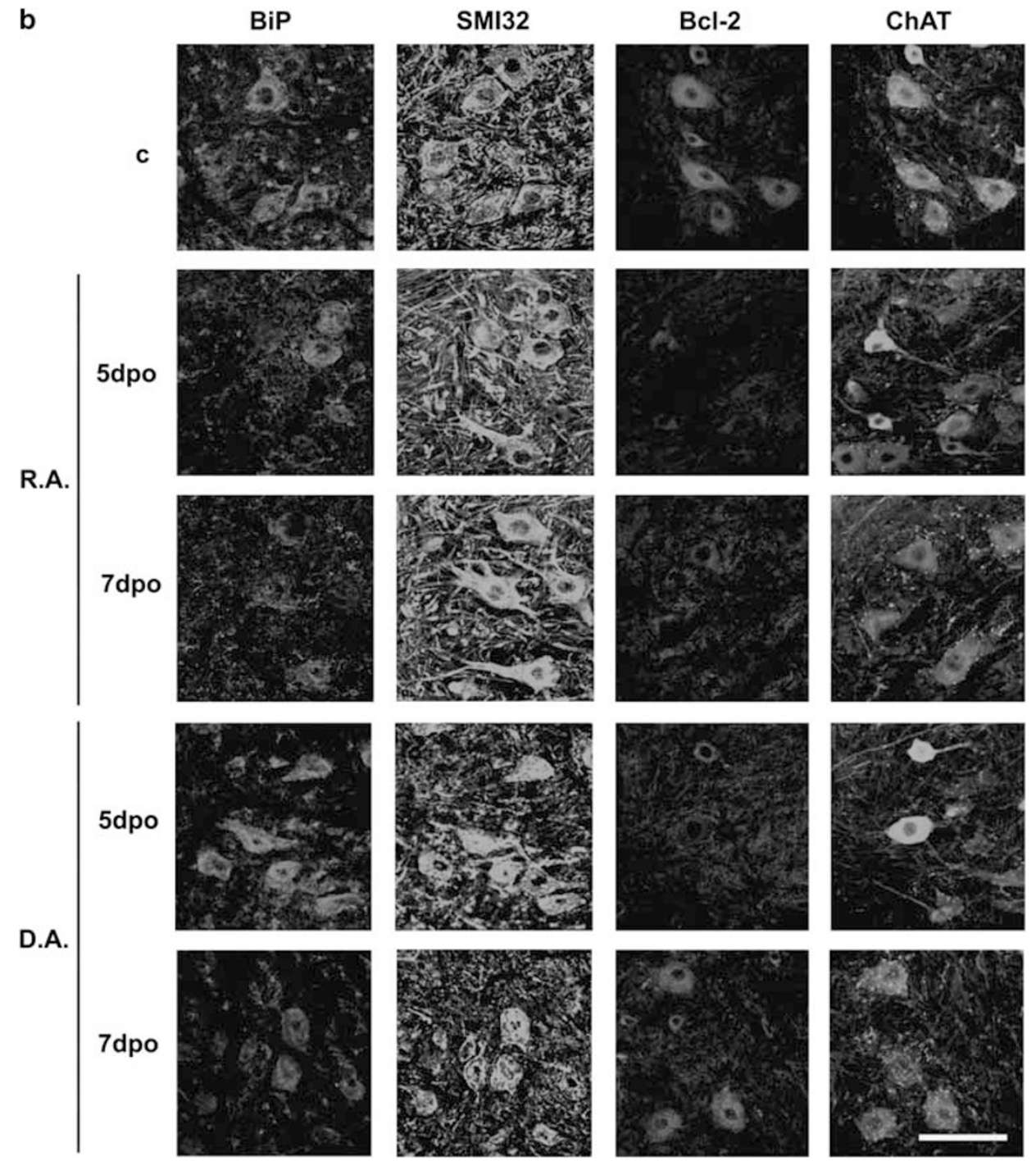

Figure 4 (a) Western blots and histogram showing the analysis of BiP protein levels in control animals (c), root avulsed (R.A) and distal axotomized (D.A) ventral horns ipsilateral (i) and contralateral (co) to the lesion. (b) Microphotographs showing immunostaining for BiP versus neurofilament (SMI32) and for Bcl2 versus ChAT in both injury models at different time points. Bar $=200 \mu \mathrm{m}$. ${ }^{\star} P<0.05$

whether autophagy might be implicated. For that purpose, we analyzed three markers of autophagy in spinal cord sections of control and lesioned animals: LC3, Beclin, and Lamp-1. The increase and redistribution of conjugated LC3-II was analyzed by western Blot, and we observed a significant increase in the conversion from LC3-I to LC3-II by 3 dpo in both ipsilateral $(6.9 \pm 1.8$ fold and 11.7 \pm 5.6$)$ and contralateral $(4.7 \pm 0.6$ and $10 \pm 5.3$ fold $)$ sides of the 

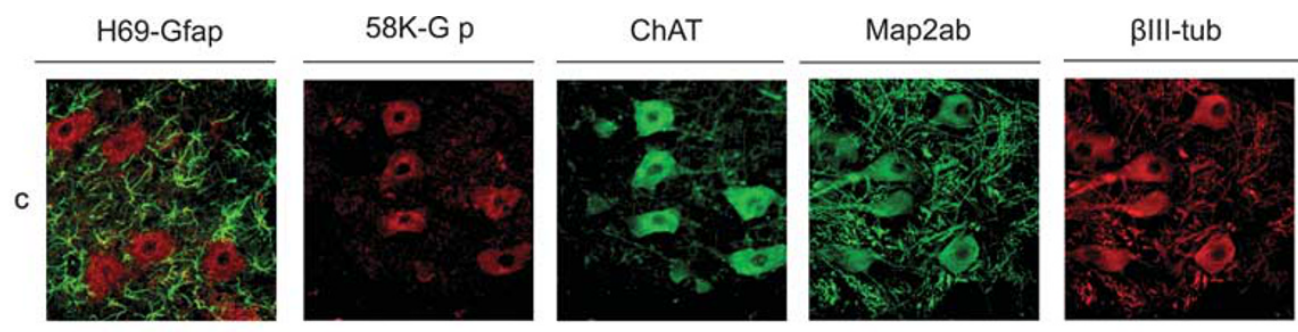

alpha-giantin
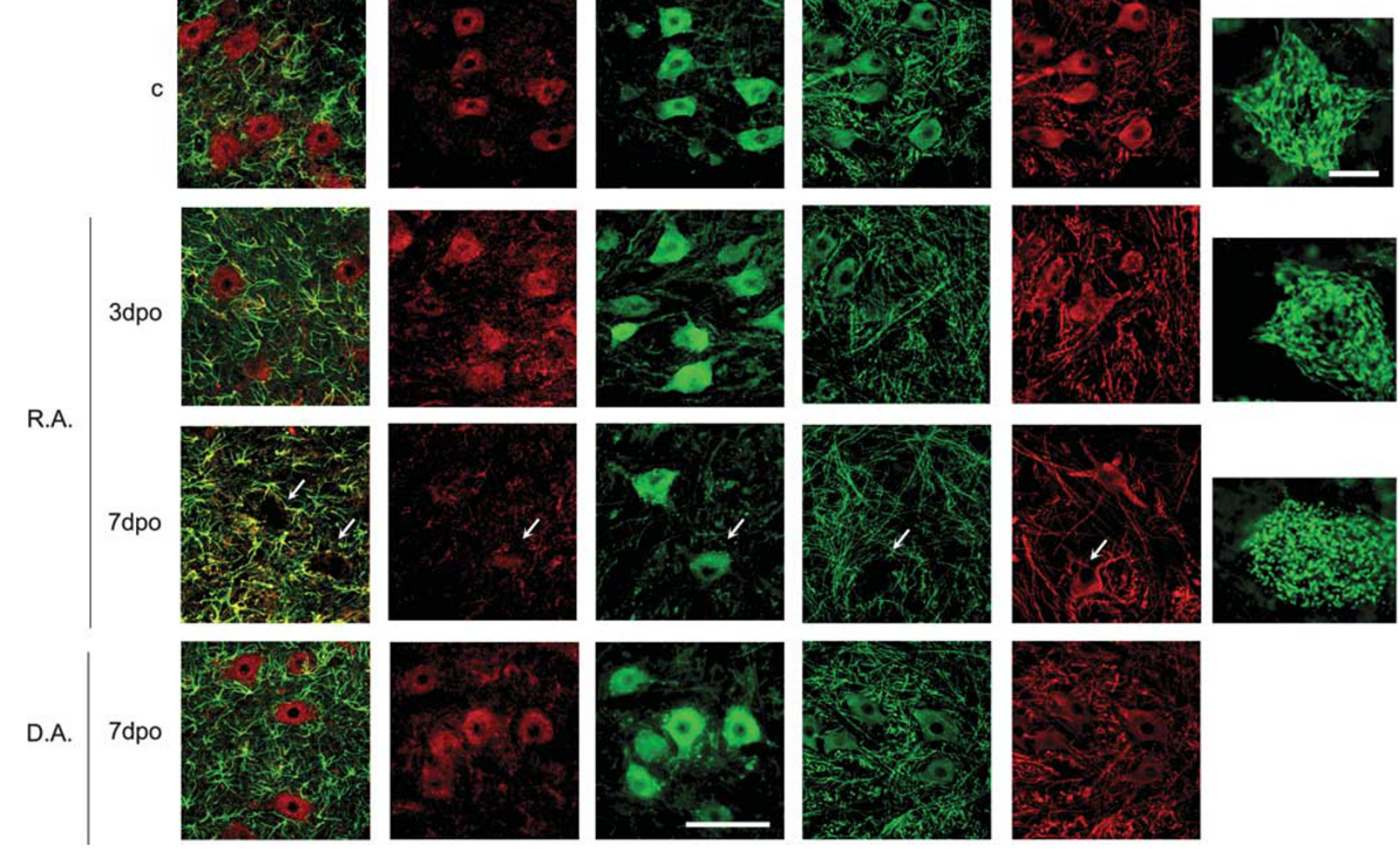

Figure 5 Microphotographs of control, root avulsed (R.A) and axotomized (D.A) MNs immunostained for an ER structural protein with the antibody H69(red) versus GFAPpositive astrocytes (green); for a Golgi apparatus structural protein with the antibody $58 \mathrm{~K}$ (red) versus ChAT (green) and cytoskeletal proteins such as Map2 a/b (green) versus $\beta$-Tubulin III (red) at different time points. Another marker ( $\alpha$-giantin) was used to better illustrate the fragmentation of the Golgi apparatus in the root avulsed MNs at different time points. Bar $=100 \mu \mathrm{m}$ for all microphotographs except for $\alpha$-giantin, in which bar $=40 \mu \mathrm{m}$. Arrows indicate where MNs are located

ventral horn, after root avulsion and distal axotomy, respectively (Figure $6 \mathrm{a}$ ). Thereafter, the protein levels returned to basal levels in both types of injury. At the same time point, 3 dpo, Beclin-1 levels reached a statistically significant increase to $4.4 \pm 0.1$ fold in ipsilateral ventral horn after root avulsion, and to $4.1 \pm 1.3$ and $4.7 \pm 1.3$ fold in the ipsilateral and the contralateral ventral horns after distal axtomy (Figure 6a). Confocal analysis showed that Beclin-1 presented a speckled autophagosome-like pattern of distribution in the MNs after both types of injury by $3-5 \mathrm{dpo}$ (Figure 6b).

Formed autophagosomes develop into mature degradative vacuoles by progressive fusion with late endosomes and lysosomes. Therefore, we analyzed by immunohistochemistry the distribution of a $110-\mathrm{kDa}$ lysosomal membrane glycoprotein (Lamp-1), which has been reported to be essential for the correct fusion with the autophagosome. ${ }^{33}$ Control animals revealed a weak immunostaining for Lamp-1, indicating basal lysosomal traffic (Figure 7). At 3 days after root avulsion, the Lamp-1 immunostaining increased substantially in MNs after both types of injury. However, from 5 days onwards the lysosomal marker completely disappeared only in root-avulsed MNs (Figure 7). Contralateral MNs maintained the Lamp-1 staining observed at 3 dpo at all time points analyzed (data not shown). In contrast, in MNs after distal axotomy, Lamp-1 immunoreactivity maintained the same earlier profile with sustained high staining from 3 dpo till $7 \mathrm{dpo}$, when it returned to basal levels (Figure7 and data not shown). In this model, contralateral MNs had also an increased immunoreactivity for Lamp-1 at all time points analyzed. We discarded anomalies in lysosomal content by analyzing cathepsin $b$ expression, which confirmed a normal distribution in avulsed MNs at 7 dpo (Figure 7).

These results indicated that autophagy is initiated following nerve injury independently of the distance and severity of the lesion. However, the normal autophagy outflow might be compromised in degenerating MNs in comparison with nondegenerating ones.

BiP overexpression protect root-avulsed MNs. Considering that $\mathrm{BiP}$ is a key chaperone involved in the regulation of autophagy and because of the different dynamic regulation observed in degenerating versus non-degenerating MNs, we promoted its overexpression using adenoviral vectors. Intratechal injection of the virus at the lumbar region resulted in infection of all neural cell types (Supplementary Figure 1), including MNs. We delivered the virus immediately after root avulsion, and followed up the animals for 3 weeks. The histological assessment showed a significant increase in the number of surviving MNs, from $37.7 \pm 2.4 \%$ in the untreated to 
a
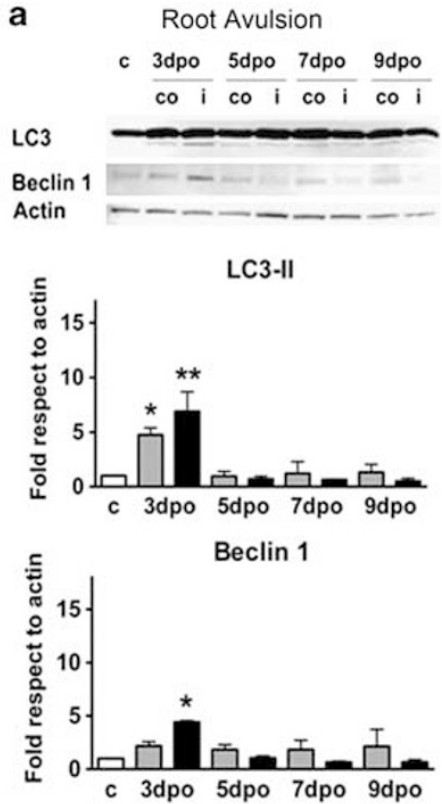

Distal Axotomy
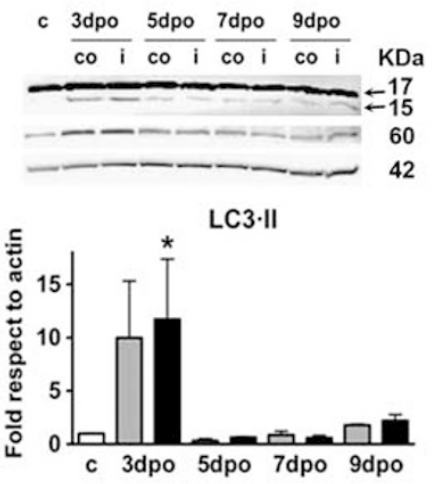

Beclin 1

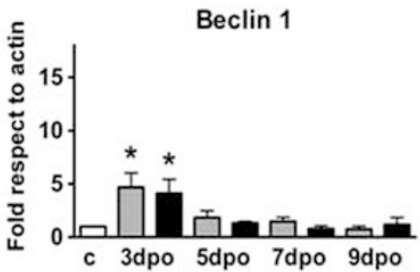

b
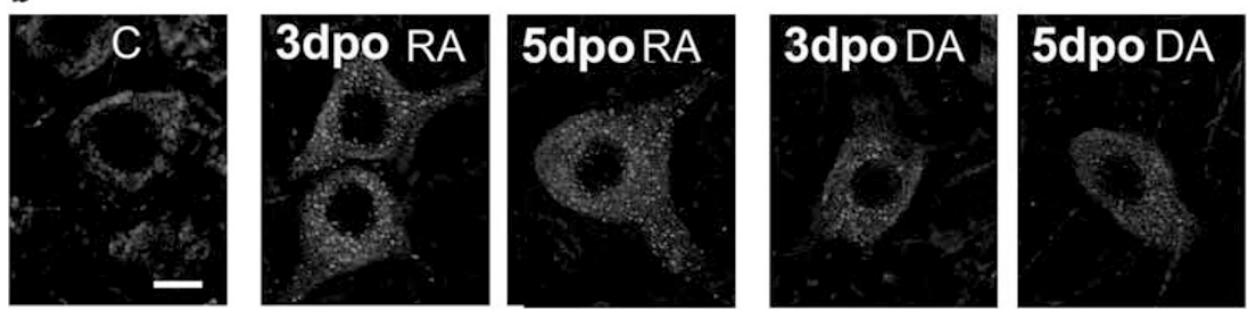

Figure 6 (a) Western blots of LC3I (superior arrow), LC3II (inferior arrow) and Beclin-1 from L4-L5 ventral spinal cords segments of control and lesioned animals at different days post-operation (dpo), referred to actin levels in control (c), contralateral (co) and ipsilateral (i) sides. ${ }^{*} P<0.05$, ${ }^{* *} P<0.01$. (b) Confocal images of the distribution of Beclin-1 in the MNs from control rats (C), the root avulsed (RA) and the distal axotomy (DA) models. Bar $=100 \mu \mathrm{m}$

$54.7 \pm 5.6 \%$ per section in the root-avulsed rats treated with AdCMVBiP (Figure 8a). We analyzed molecular changes related to neuroprotection in samples taken at $7 \mathrm{dpo}$, when the most obvious changes in the root-avulsed MNs were observed. The expression of $\mathrm{Bcl}-2$ in the avulsed MNs was restored in the $\mathrm{BiP}$-overexpressing rats compared with their respective controls (Figure $8 \mathrm{~b}$ ). However, the expression of Beclin-1, Lamp-1, and MAP2A did not show differences between control and BiP-treated rats after root avulsion (data not shown). Thus, we analyzed treated and untreated rats at $3 \mathrm{dpo}$, when obvious upregulation of LC3II was observed in injured animals. In avulsed rats treated with AdCMVBiP there was a inversion in the LC3 bands with reduced formation of LC3II (Figure 8c), suggesting either lack of autophagy or a rapid dissipation due to increased autophagic flow that prevent LC3II accumulation. We also checked the corresponding increase in $\mathrm{BiP}$ levels. We observed higher levels, although without statistical significance in part due to the normal increase produced at 3 dpo after root avulsion, as observed in samples from rats treated with $A d C M V \beta$ gal. These findings suggested that overexpression of $\mathrm{BiP}$ promotes survival of root-avulsed $\mathrm{MNs}$ and that neuroprotection may be operating through a specific function on the autophagic flow, as well as the activation of Bcl-2 pro-survival factor.

\section{Discussion}

We aimed to determine the molecular and cellular changes that contribute to the degeneration of MNs following spinal root avulsion. We found that root avulsion caused ER stress, revealed by an early activation of the IRE $1 \alpha / \mathrm{Xbp} 1$ and ATF4mediated branches of the UPR, and initiation of autophagy, with concomitant disorganization of the cytoskeleton and organelles from the secretory pathway. In contrast, the regenerative $\mathrm{MN}$ reaction following distal axotomy and reconnection did not induce ER stress, and it triggered only autophagy. The GRP78/BiP protein-level reduction found specifically in MNs around $7 \mathrm{dpo}$ after root avulsion seems to be one of the key events in the degenerative process, as its overexpression led to a significant increase in MN survival.

The $\mathrm{MN}$ reaction after axotomy is produced by retrograde signals that convey information of axon damage from the periphery to the cell body. At the very beginning, calcium homeostasis disturbances $^{9}$ and trophic factor withdrawal ${ }^{10}$ occurs after axotomy and participate in this neuronal response. Both events had already been linked to ER stress in vitro. ${ }^{34}$ Therefore, it was of interest to investigate the presence of ER stress after axotomy and its relationship with $\mathrm{MN}$ death in vivo. To cope with ER stress, the cell may 


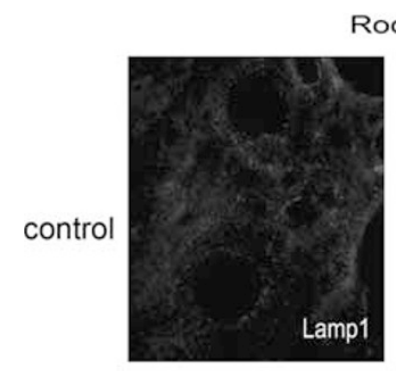

Root Avulsion
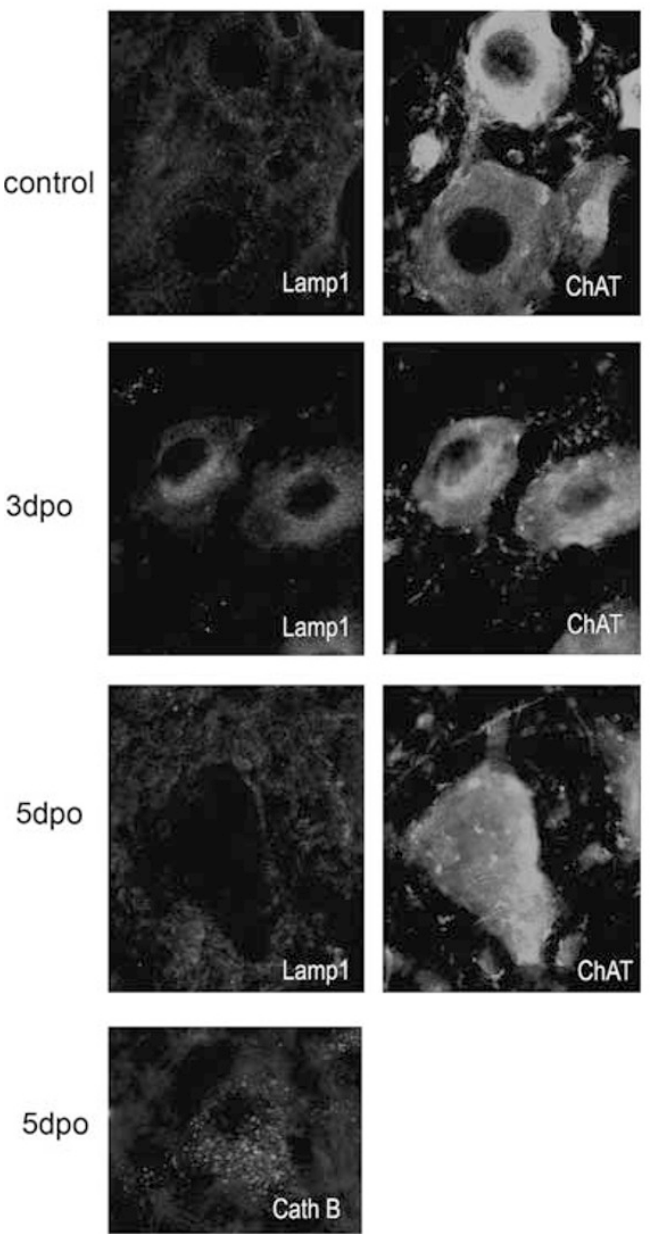
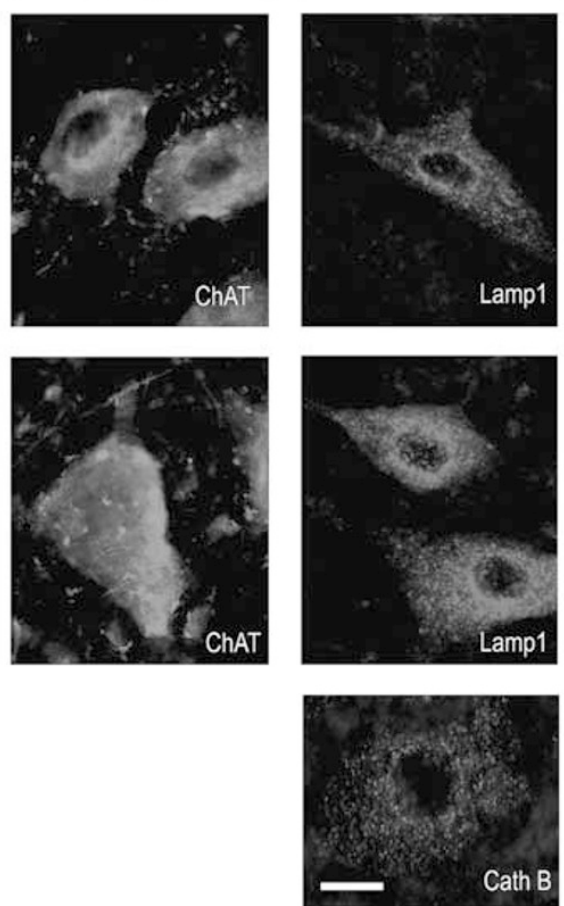

th $B$
Distal Axotomy
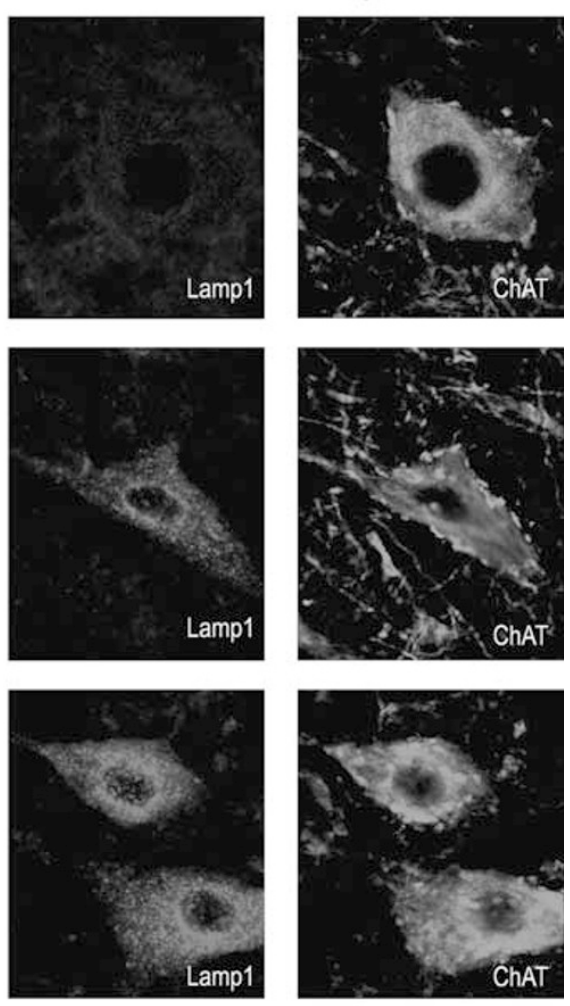

Figure 7 Immunohistochemical analysis of Lamp-1 lysosomal distribution versus ChAT immunostaining in MNs from root avulsion and nerve section models at different time points. The presence of another lysosomal marker Cathepsin B was also analyzed at $5 \mathrm{dpo}$. Bar $=40 \mu \mathrm{m}$

respond activating UPR and autophagic events. We have found that following root avulsion, degenerating MNs initially suffer ER stress and respond increasing the ribonuclease activity of IRE $1 \alpha$ and raising ATF4 levels. These molecular events are distinctive from MNs that do not degenerate after distal nerve lesion and are allowed to regenerate. Considering the influence of trophic factor withdrawal from proximal nerve stump for axotomized MN survival, it is possible that this might trigger UPR activation as a protective self-defense mechanism. In fact, it has been proposed that ATF4 accumulation allows the cell to survive for a longer period, following a process of slow program death in contrast to a faster apoptotic program. ${ }^{35}$ This slow process culminates with severe Golgi and ER fragmentation together with cytoskeletal abnormalities in the microtubule network that were not apparent in nondegenerating MNs. Considering that prolonged UPR leads to cell death via apoptosis, we expected to find any sign in this respect but we failed what was in agreement with previous reports suggesting rather a necrosis process implicated in the MN death. ${ }^{6,7}$ Thus, considering that ER stress can trigger autophagy and continued autophagy is detrimental to cell survival as a consequence of excess organelle and macromolecular catabolism, we investigate the presence of that event. Autophagy may be triggered by a PERKindependent ATF4 accumulation that induces LC3II formation. ${ }^{35}$ IRE $1 / \mathrm{Xbp} 1$ has been also implicated in the initiation of autophagy. ${ }^{21}$ In the root-avulsed model, ATF4 accumulation and IRE1/Xbp1 activation in MNs was found coincident with early LC3 II and Beclin-1 accumulation and it persisted thereafter. It was surprising to find early detection of these events also in non-degenerating MNs, in which UPR was not triggered. These results suggested that although in gross, autophagy was early activated in both cases, substantial differences make MNs to render vulnerable to cell death or not. Autophagy might be initiated likely due to the rapid activation of several calcium-dependent kinases, such as calmodulin kinase II, because of axonal membrane rupture and massive calcium influx. ${ }^{36}$ Thus, autophagy may be activated as a self-defense mechanism in response to the insult. In damaged MNs, this activation may supply energy while the cell re-programs its mode to initiate axonal regeneration. ${ }^{5}$ However, the autophagy process may be different depending on concomitant activation of other mechanisms, such as the UPR, to be detrimental or to 

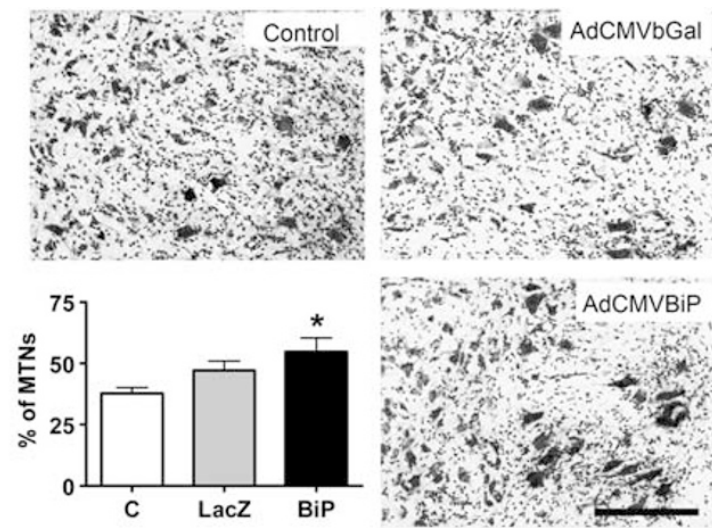

b
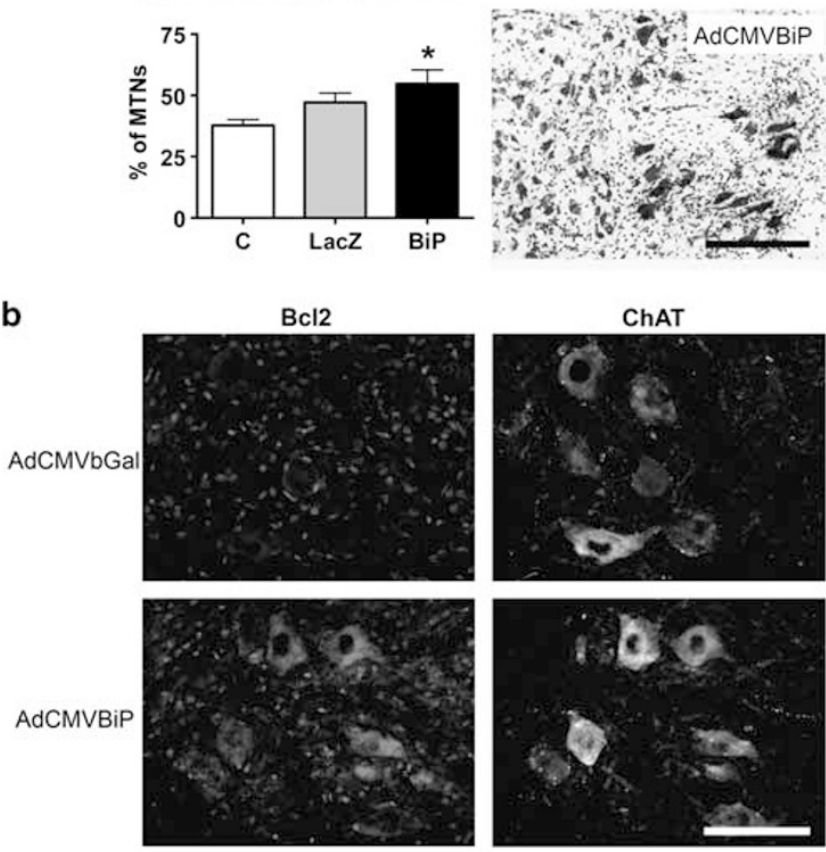

C
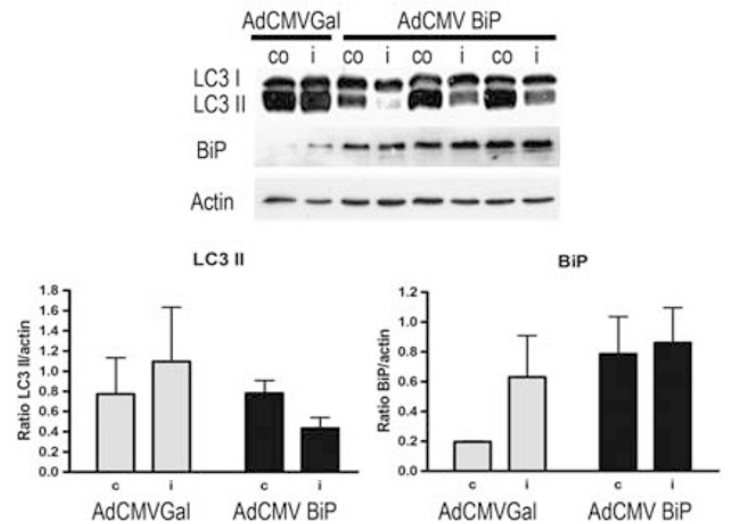

Figure 8 (a) Representative pictures of cresyl-violet stained ipsilateral ventral horns of untreated $(U)$ root-avulsed rats showing the reduction of MNs at $21 \mathrm{dpo}$ and the injured rats treated with either the AdCMVbGal or the AdCMVBiP viral vectors. The histogram represents the mean percentage of surviving MNs in the ipsilateral with respect to contralateral side. ${ }^{*} P<0.05$. (b) Immunohistochemical analysis of the expression of Bcl2 in MNs labeled with anti-ChAT at 7dpo in rootavulsed rats treated with the different vectors. Bar $=100 \mu \mathrm{m}$. (c) Representative membranes of western blots for LC3I (top band), LC3II (bottom band), and BiP from L4-L5 ventral spinal cord segments of injured rats treated with either AdCMVbGal or AdCMVBiP viral vectors. Bar graph representations (bottom) of band densitometry respective to actin levels $(n=4)$. C stands for contralateral and I for ipsilateral

become protective in regenerating MNs. We have found two molecular signatures that mark these differences: vanishing of Lamp-1 staining from 5-days post lesion, and a distinctive decrease of BiP levels around $7 \mathrm{dpo}$. The total absence of
Lamp-1 is unusual, and we cannot discard that may be an artefact due to changes in cell phenotype that affect antigen presentation in the immunohistochemical analysis, but it seems to be specific for Lamp-1 as cathepsin B was well present. Lamp-1 is essential for the last steps in the autophagic flow and its reduction may affect also the resolution of the protective mechanism. On the other hand, we have found that BiP level is a key event in the survival of MNs following root avulsion. It is well known that BiP has essential roles in orchestrating ER stress and managing misfolded proteins through interactions with proteasome and autophagic initiation. ${ }^{17,27}$ In light of ours results, it seems that raising the levels of BiP early after lesion modifies the outcome of the autophagic flow leading to promotion of survival pathways with $\mathrm{Bcl}-2$ upregulation. Both events might be linked as $\mathrm{Bcl}-2$ can regulate autophagy by sequestrating Beclin-1 and thus, inhibiting the promotion of autophagy. ${ }^{37-39}$ Therefore, the increase of $\mathrm{Bcl}-2$, promoted by BiP overexpression, may decrease caspase-independent cell death ${ }^{39}$ after root avulsion. Although we have not seen changes in Beclin-1 after Bcl-2 overexpression, further analyses of Bcl-2 on the autophagic flux should be conducted in order to shed light into these mechanisms. It is out of the scope of this study to decipher the detailed nature of these interactions in the context of MN degeneration, but we think that BiP-Bcl2 connection and the autophagic process deserve further study in relation to neuronal degeneration and survival after axonal damage. It may also lead to therapeutical pespectives in spinal cord trauma and MN diseases, as the root avulsion model has been proposed as non-genetic model for some neurodegenerative diseases. ${ }^{4}$ In this regard, gene therapy promoting overexpression of $\mathrm{BiP}$ seems a promising strategy.

\section{Materials and Methods}

Surgical procedures. Spraque-Dawley female rats aged 12 weeks were kept under standard conditions of light and temperature and fed with food and water ad libitum. Surgical procedures were carried out under sodium pentobarbital $(40 \mathrm{mg} / \mathrm{kg}$, i.p.) anesthesia. For spinal root injury, an extravertebral avulsion of $L 4$ and $L 5$ roots was carried out as previously described. ${ }^{5}$ Briefly, after a midline skin incision, the right sciatic nerve was identified and the $\mathrm{L} 4-\mathrm{L} 5$ spinal nerves were separated. A moderate traction was applied away from the intervertebral foramina, delivering the mixed spinal nerves that contained the motor and sensory roots and dorsal root ganglia. The left roots were kept intact. To produce distal axotomy, the right sciatic nerve was exposed at midthigh and freed from surrounding tissues; then, the nerve was transected and immediately repaired by fascicular suture (10-0, Ethicon). ${ }^{3}$ After both types of lesions, the wound was sutured by planes, disinfected with povidone iodine and the animals allowed recovering in a warm environment. Groups of rats $(n=4-5)$ with root avulsion or nerve lesion and unoperated controls were used at different time intervals $(1,3,5,7,10$ and 21 days post operation (dpo)). All procedures involving animals were approved by the Ethics Committee of our institution, and followed the European Community Council Directive 86/609/EEC.

Construction, purification, and infection with recombinant adenoviruses. CDNA encoding grp78 (ATCC, LGC Promochem) was cloned into the pAC.CMV shuttle vector. Recombinant adenoviruses were constructed by homologous recombination in HEK293 cells as described earlier, ${ }^{40}$ and were replication deficient and included the cytomegalovirus (CMV) promoter. A control adenovirus-expressing bacterial $\beta$-galactosidase (AdCMV $\beta$ gal) was a kind gift of C.B. Newgard (Duke University, Durham, NC, USA). Viruses were purified using the Vivapure AdenoPackTM 20 kit according to the instructions of the manufacturer (Sartorius, Goettingen, Germany). For viral infection, immediately after root avulsion the animals were injected with $14 \mu$ l of either AdCMVgrp78 or AdCMV $\beta$ gal viruses $\left(10^{8} \mathrm{pfu} / \mathrm{ml}\right)$ by means of a 30 -gauge needle into the thecal space at the lumbar site. 
Table 1 List of antibodies used for Immunohistochemistry (IHC) and/or Western blot (WB)

\begin{tabular}{llll}
\hline Name & Host & & Dilution for IHC \\
\hline Cleaved casp 3 (Asp175) & Polyclonal & Cell Signaling Technologies, Danvers, MA, USA & $1 / 20$ \\
GRP78/BiP & Polyclonal & Stressgen Biotechnologies, Victoria, BC, Canada, & $1 / 200$ \\
CREB2/ATF4 & Polyclonalt & Santa Cruz Biotechnologies, Santa Cruz, CA, USA & $1 / 50$ \\
H69 & Polyclonal & Developmental Studies Hybridoma Bank, IA, USA & $1 / 100$ \\
NeuN & Monoclonal & Chemicon, Temecula, CA, USA & $1 / 100$ \\
$\alpha$-giantin & Monoclonal & kindly provided by Enrique Claro & $1 / 1000$ \\
58K-Golgi prot. & Polyclonal & Abcam, Cambridge, UK & $1 / 1000$ \\
Casp 12 & Polyclonal & Sigma & $1 / 350$ \\
Beclin-1 & Polyclonal & Abcam & $1 / 200$ \\
Lamp-1 & Polyclonal & Developmental Studies Hybridoma Bank & $1 / 200$ \\
ChAT & Polyclonal & Chemicon & $1 / 75$ \\
GFAP & Polyclonal & Dako & $1 / 1000$ \\
SMI32 & Monoclonal & Stenberger Monoclonals, Baltimore, MD, USA & $1 / 2500$ \\
MAP2 & Mouse & Sigma & $1 / 500$ \\
$\beta$-III-tubulin & Mouse & Covance, Berkeley, CA, USA & $1 / 100$ \\
CC1/APC & Mouse & Abcam, Cambridge, UK & $1 / 400$ \\
IB4 & Polyclonal & Vector, Burlingame, CA, USA & $1 / 1000$ \\
Bcl-2 & Polyclonal & BD Biosciences, Franklin Lakes, NJ, USA & $1 / 200$
\end{tabular}

At 1-minute post infusion, the needle was removed and the incision closed. Untreated animals with root avulsion were also used as controls.

Histology and immunohistochemistry. Control and lesioned animals were deeply anesthetized with sodium pentobarbital $(60 \mathrm{mg} / \mathrm{kg}$, i.p.) and perfused with $4 \%$ paraformaldehyde in phosphate-buffered saline (PBS) at 3, 5, 7, and $10 \mathrm{dpo}$ ( $n=4$ at each time post lesion). The L4 and L5 segments (5-mm total length) of the spinal cord were removed, post fixed in the same fixative for $24 \mathrm{~h}$ and cryopreserved in $30 \%$ sucrose. Transverse sections (20- $\mu \mathrm{m}$ thick) were cut with a cryotome (Leica, Heidelberg, Germany). The sections were distributed in 50 series of five sections each, and each series was prepared for immunohistochemical analysis by blocking with $10 \%$ bovine serum in tris-buffered saline (TBS) for 2 days at $4^{\circ} \mathrm{C}$ with different primary antibodies (Table 1). After washes, sections were incubated for 1 day at $4^{\circ} \mathrm{C}$ with biotynilated secondary antibodies (Vector, Burlingame, CA, USA, 1:200) with Cy-2 or Cy-3 conjugated donkey anti-rabbit antibodies (Jackson Immunoresearch, West Grove, PA, USA, 1:200). Slides were counterstained with DAPI (Sigma, St Louis, MO, USA, 1:1000), dehydrated and mounted with DPX (Fluka, Buchs, Switzerland). Sections from different time points of injured and control animals were processed in parallel for immunohistochemistry. Images of the ventral area of the spinal cord were taken under the same exposure time, sensibility, and resolution for each marker analyzed, with the aid of a digital camera (Olympus DP50) attached to the microscope (Olympus BX51). Confocal microscope examinations were performed with a Leica TCS SP2 AOBS laser scanning confocal system (Leica). Images were collected with a 1.4 numerical aperture oil-immersion $63 \times$ objective. Confocal images were obtained using two separate photomultiplier channels, either concurrently or in separate runs, and were separately projected and merged using a pseudocolor display showing green for Cy2, red for Cy3, and yellow for colocalization.

Spinal cords obtained from animals at $21 \mathrm{dpo}$ were cut at $40-\mu \mathrm{m}$ thickness. One series of five sections (separated by $200 \mu \mathrm{m}$ ) of each mm for each spinal cord was stained with cresyl violet for MN counting as previously described. ${ }^{5}$ Only cells localized in the lateral ventral horn, with diameters ranging 30-70 $\mu \mathrm{m}$, with a prominent nucleolus and polygonal in shape were accepted to selectively count the population of $\alpha$-MNs.

Spinal cord sections from animals receiving the injection of AdCMV $\beta$ gal virus were incubated in 5-bromo-4-chloro-3-indolyl-b-D-galactopyranoside (X-gal, $1 \mathrm{mg} / \mathrm{ml}$ final concentration from a $20 \mathrm{~m} / \mathrm{ml}$ stock solution in $\mathrm{N}, \mathrm{N}$-dimethyl formamide) and buffer $100 \mathrm{mM}$ sodium phosphate, $1.3 \mathrm{mM} \mathrm{MgCl}, 3 \mathrm{mM} \mathrm{K} \mathrm{K}_{3} \mathrm{Fe}(\mathrm{CN})_{6}, 3 \mathrm{mM}$ $\mathrm{K}_{4} \mathrm{Fe}(\mathrm{CN})_{6}$ at $\mathrm{pH} 7.3$ for $3 \mathrm{~h}$ at $37^{\circ} \mathrm{C}$ and mounted on slides as previously described. ${ }^{41}$

For Terminal dUTP Nick End Labeling (TUNEL) staining, tissue sections were rinsed in Tris buffer ( $10 \mathrm{mM}, \mathrm{pH} 8)$ and EDTA $(5 \mathrm{mM})$, and then immersed in the same buffer plus proteinase $\mathrm{K}(20 \mathrm{~g} / \mathrm{ml})$ for $15 \mathrm{~min}$ at room temperature. After washes with EDTA, sections were incubated for $10 \mathrm{~min}$ in TdT buffer (Tris 30 , $140 \mathrm{mM}$ sodium cacodilate, $1 \mathrm{mM}$ cobalt chloride, $\mathrm{pH} 7.7$ ), and then in TdT buffer plus $0.161 \mathrm{U} / \mathrm{I}$ TdT enzyme (Terminal Transferase, 3333566 Roche, Manheim,
Germany) and $0.0161 \mathrm{nmol} / /$ biotin-16-dUTP (1093070, Roche) for $30 \mathrm{~min}$ at $37^{\circ} \mathrm{C}$. The reaction was stopped with citrate buffer $(300 \mathrm{mM}$ sodium chloride, $30 \mathrm{mM}$ sodium citrate, $5 \mathrm{mM}$ EDTA). After washes, sections were incubated with HRPconjugated streptavidin $(1: 400$, SA5004, Vector Laboratories, Burlingame, CA, USA) and the peroxidase reaction product was visualized in a solution containing $0.02 \% \mathrm{DAB}, 2.4 \%$ nickel ammonium, $0.04 \%$ chloride ammonium, $0.2 \%$ glucose $\mathrm{D}+$, and $0.0027 \%$ glucose oxidase in $0.1 \mathrm{M}$ acetate buffer ( $\mathrm{pH} 6.0$ ). The positive controls used for TUNEL and caspase-3 immunostaining were kindly provided by Dr Bernardo Castellano and Dra. Berta Gonzalez from a well-characterized in vivo model of excitotoxicity in postnatal rats. ${ }^{42}$

Protein extraction and western blot. Rats were anesthetised and decapitated at $3,5,7$, and 9 days for sample preparation ( $n=3$ per time point). The L4-L5 spinal cord segments were removed and divided into quarters to isolate the ventral part of each side. For protein extraction, the ipsilateral and contralateral ventral parts of L4-L5 cord segments were separately homogenized in RIPA modified buffer (50 mM Tris-HCl ph 7.5, $1 \%$ Triton X-100, 0.5\% DOC Na, 0.2\% SDS, $100 \mathrm{mM} \mathrm{NaCl}, 1 \mathrm{mM} \mathrm{EDTA}$ ) with $10 \mu / \mathrm{ml}$ of a Protease Inhibitor Cocktail (Sigma). After clearance, protein concentration was measured by the BCA method assay (BCA Protein Assay kit, Pierce, Rockford, IL, USA). A measure of $20 \mu \mathrm{g}$ of protein were loaded from each sample in $12 \%$ SDS-polyacrylamide gels. The transfer buffer was $25 \mathrm{mM}$ trizma-base, $192 \mathrm{mM}$ glycine, $20 \%$ (v/v) methanol, pH 8.4. The primary antibodies used are summarized in Table 1. The membrane was visualized by enhanced chemiluminiscence method, and the images analyzed with Gene Snap and Gene Tools softwares, and Gene Genome apparatus (Syngene, Cambridge, UK). The positive controls for ATF6, phosporylated and total elF2 $\alpha$, CHOP and caspase 12 are thoracic eight (T8) samples of animals submitted to spinal cord injury $(\mathrm{C}+)^{40}$

Statistical analysis. All values are presented as mean \pm S.E.M. Statistical comparisons between means were made by one-way ANOVA followed by Dunnett's multiple comparison tests. A probability of $95 \%$ was taken to indicate significant differences.

Acknowledgements. We thank $\mathrm{Dr}$ Rosa Gasa from the Department of Diabetes, IDIBAPS, Barcelona (Spain) for her technical support and advice in the preparation and use of adenoviral vectors, and Drs Berta Gonzalez and Bernardo Castellano for helpful advice on the study of TUNEL and caspase 3 activation. This work was supported by grants from the Ministerio de Ciencia y Tecnología (Grants SAF2006-08682, SAF2009-12495), the Ministerio de Sanidad (FIS PI081932) and funds from Red de Terapia Celular (TERCEL) and from the Centro de investigación biomédica en Red para enfermedades neurodegenerativas (CIBERNED) of Spain.

1. NissI F. ber die Veraenderungen der Ganglienzellen amFacialiskern des Kaninchens nach Ausreissung der Nerven. Allg Z Psychiatr 1892; 48: 197-198. 
2. Hanz S, Fainzilber M. Retrograde signaling in injured nerve-the axon reaction revisited J Neurochem 2006; 99: 13-19.

3. Valero-Cabre A, Tsironis K, Skouras E, Navarro X, Neiss WF. Peripheral and spinal motor reorganization after nerve injury and repair. J Neurotrauma 2004; 21: 95-108.

4. Martin LJ, Kaiser A, Price AC. Motor neuron degeneration after sciatic nerve avulsion in adult rat evolves with oxidative stress and is apoptosis. J Neurobiol 1999; 40: 185-201.

5. Penas C, Casas C, Robert I, Fores J, Navarro X. Cytoskeletal and activity-related changes in spinal motoneurons after root avulsion. J Neurotrauma 2009; 26: 763-779.

6. Li L, Houenou LJ, Wu W, Lei M, Prevette DM, Oppenheim RW. Characterization of spina motoneuron degeneration following different types of peripheral nerve injury in neonatal and adult mice. J Comp Neurol 1998; 396: 158-168.

7. Park OH, Lee KJ, Rhyu IJ, Geum D, Kim H, Buss R et al. Bax-dependent and -independent death of motoneurons after facial nerve injury in adult mice. Eur J Neurosci 2007; 26 1421-1432.

8. Ziv NE, Spira ME. Axotomy induces a transient and localized elevation of the free intracellular calcium concentration to the millimolar range. J Neurophysiol 1995; 74 2625-2637.

9. Titmus MJ, Faber DS. Axotomy-induced alterations in the electrophysiological characteristics of neurons. Prog Neurobiol 1990; 35: 1-51.

10. Purves D, Snider WD, Voyvodic JT. Trophic regulation of nerve cell morphology and innervation in the autonomic nervous system. Nature 1988; 336: 123-128.

11. Spacek J, Harris KM. Three-dimensional organization of smooth endoplasmic reticulum in hippocampal CA1 dendrites and dendritic spines of the immature and mature rat. J Neurosci 1997; 17: 190-203.

12. Westrum LE, Gray EG. New observations on the substructure of the active zone of brain synapses and motor endplates. Proc R Soc Lond B Biol Sci 1986; 229: 29-38.

13. Feiguin F, Ferreira A, Kosik KS, Caceres A. Kinesin-mediated organelle translocation revealed by specific cellular manipulations. J Cell Biol 1994; 127: 1021-1039.

14. Faitova J, Krekac D, Hrstka R, Vojtesek B. Endoplasmic reticulum stress and apoptosis Cell Mol Biol Lett 2006; 11: 488-505.

15. Penas C, Guzman MS, Verdu E, Fores J, Navarro X, Casas C. Spinal cord injury induces endoplasmic reticulum stress with different cell-type dependent response. J Neurochem 2007; 102: 1242-1255.

16. Yoshida H. ER stress and diseases. Febs J 2007; 274: 630-658.

17. Tamura T, Cormier JH, Hebert DN. Sweet bays of ERAD. Trends Biochem Sci 33; 2008 298-300.

18. Kroemer G, Levine B. Autophagic cell death: the story of a misnomer. Nat Rev Mol Cell Bio 2008; 9: 1004-1010.

19. Bertolotti A, Zhang Y, Hendershot LM, Harding HP, Ron D. Dynamic interaction of BiP and ER stress transducers in the unfolded-protein response. Nat Cell Biol 2000; 2: 326-332.

20. Mori K. Tripartite management of unfolded proteins in the endoplasmic reticulum. Cell 2000; 101: 451-454.

21. Ogata M, Hino S, Saito A, Morikawa K, Kondo S, Kanemoto S et al. Autophagy is activated for cell survival after endoplasmic reticulum stress. Mol Cell Biol 2006; 26: 9220-9231.

22. Kouroku $Y$, Fujita E, Tanida I, Ueno $T$, Isoai A, Kumagai $H$ et al. ER stress (PERK elF2alpha phosphorylation) mediates the polyglutamine-induced LC3 conversion, an essential step for autophagy formation. Cell Death Differ 2007; 14: 230-239.

23. Ito M, Nakagawa H, Okada T, Miyazaki S, Matsuo S. ER-stress caused by accumulated intracistanal granules activates autophagy through a different signal pathway from unfolded protein response in exocrine pancreas cells of rats exposed to fluoride. Arch Toxicol 2009; 83: 151-159
24. Ohsumi Y. Molecular dissection of autophagy: two ubiquitin-like systems. Nat Rev Mol Cell Biol 2001; 2: 211-216

25. Sou YS, Tanida I, Komatsu M, Ueno T, Kominami E. Phosphatidylserine in addition to phosphatidylethanolamine is an in vitro target of the mammalian Atg8 modifiers, LC3, GABARAP, and GATE-16. J Biol Chem 2006; 281: 3017-3024.

26. He C, Klionsky DJ. Regulation mechanisms and signaling pathways of autophagy. Annu Rev Genet 2009; 43: 67-93

27. Li J, Ni M, Lee B, Barron E, Hinton DR, Lee AS. The unfolded protein response regulator GRP78/BiP is required for endoplasmic reticulum integrity and stress-induced autophagy in mammalian cells. Cell Death Differ 2008; 15: 1460-1471.

28. Yoshida H, Oku M Suzuki M, Mori K. pXBP1(U) encoded in XBP1 pre-mRNA negatively regulates unfolded protein response activator $\mathrm{pXBP} 1(\mathrm{~S})$ in mammalian ER stress response. J Cell Biol 2006; 172: 565-575.

29. Danial NN, Korsmeyer SJ. Cell death: critical control points. Cell 2004; 116: 205-219.

30. Hughes EN, August JT. Characterization of plasma membrane proteins identified by monoclonal antibodies. J Biol Chem 1981; 256: 664-671.

31. Waterman-Storer CM, Salmon ED. Endoplasmic reticulum membrane tubules are distributed by microtubules in living cells using three distinct mechanisms. Curr Biol 1998; 8: $798-806$.

32. Ding WX, Ni HM, Gao W, Hou YF, Melan MA, Chen X et al. Differential effects of endoplasmic reticulum stress-induced autophagy on cell survival. J Biol Chem 2007; 282: 4702-4710.

33. Binker MG, Cosen-Binker LI, Terebiznik MR, Mallo GV, McCaw SE, Eskelinen EL et al. Arrested maturation of Neisseria-containing phagosomes in the absence of the lysosomeassociated membrane proteins, LAMP-1 and LAMP-2. Cell Microbiol 2007; 9: 2153-2166.

34. Brewster JL, Linseman DA, Bouchard RJ, Loucks FA, Precht TA, Esch EA et al. Endoplasmic reticulum stress and trophic factor withdrawal activate distinct signaling cascades that induce glycogen synthase kinase-3 beta and a caspase-9-dependent apoptosis in cerebellar granule neurons. Mol Cell Neurosci 2006; 32: 242-253.

35. Milani M, Rzymski T, Mellor HR, Pike L, Bottini A, Generali D et al. The role of ATF4 stabilization and autophagy in resistance of breast cancer cells treated with Bortezomib. Cancer Res 2009; 69: 4415-4423.

36. Navarro $X$, Vivo M, Valero-Cabre A. Neural plasticity after peripheral nerve injury and regeneration. Prog Neurobiol 2007; 82: 163-201.

37. Liang XH, Kleeman LK, Jiang HH, Gordon G, Goldman JE, Berry G et al. Protection against fatal Sindbis virus encephalitis by beclin, a novel Bcl-2-interacting protein. J Virol 1998; 72: $8586-8596$.

38. Pattingre S, Tassa A, Qu X, Garuti R, Liang XH, Mizushima N et al.. Bcl-2 antiapoptotic proteins inhibit Beclin-1-dependent autophagy. Cell 2005; 122: 927-939.

39. Rashmi R, Pillai SG, Vijayalingam S, Ryerse J, Chinnadurai G. BH3-only protein BIK induces caspase-independent cell death with autophagic features in Bcl-2 null cells. Oncogene 2008; 27: 1366-1375.

40. Becker TC, Noel RJ, Coats WS, Gomez-Foix AM, Alam T, Gerard RD et al. Use of recombinant adenovirus for metabolic engineering of mammalian cells. Methods Cell Biol 1994; 43 (Part A): 161-189.

41. Mannes AJ, Caudle RM, O'Connell BC, ladarola MJ. Adenoviral gene transfer to spinal-cord neurons: intrathecal vs. intraparenchymal administration. Brain Res 1998; 793 : 1-6.

42. Acarin L, Villapol S, Faiz M, Rohn TT, Castellano B, Gonzalez B. Caspase-3 activation in astrocytes following postnatal excitotoxic damage correlates with cytoskeletal remodeling but not with cell death or proliferation. Glia 2007; 55: 954-965.

\section{Supplementary Information accompanies the paper on Cell Death and Differentiation website (http://www.nature.com/cdd)}

